\title{
Feed intake and behavior of dairy goats when offered an elevated feed bunk
}

\author{
Heather W. Neave, ${ }^{*}$ Marina A. G. von Keyserlingk, ${ }^{*}$ Daniel M. Weary, ${ }^{*}$ and Gosia Zobel ${ }^{1}$ \\ *Animal Welfare Program, Faculty of Land and Food Systems, University of British Columbia, Vancouver, British Columbia, Canada V6T 1 Z4 \\ †Animal Science, AgResearch Ltd., Ruakura Research Centre, Hamilton 3240, New Zealand
}

\begin{abstract}
Goats are browsers and select vegetation at various heights when foraging. On commercial farms, dairy goats are typically fed from low-level feed bunks. The objective of this study was to determine how feed intake and feeding behavior vary when goats are offered feed at variable heights, with the potential of evaluating the benefits of offering an elevated feeder to dairy goats. Thirteen Saanen X dairy goats were housed in a home pen with a lying area of wood shavings, where they were pre-exposed for $24 \mathrm{~d}$ to 3 feeder heights designed to result in differences in head height while feeding: floor level (head lowered relative to body), head level (head level relative to body), and elevated level (head and neck angled upward). Nine groups of 3 goats each were randomly selected and housed for 24 $\mathrm{h}$ in a test pen identical to the home pen except that it contained 1 of each of the 3 feeder heights. Each feeder contained ad libitum chopped alfalfa silage and a top-dressed corn-based supplement, refreshed twice daily. Refusals from inside and under each feeder were weighed to calculate intake. Feed intake increased with increasing feeder height (mean $\pm \mathrm{SE}$; 0.18, 0.29, and $0.34 \pm 0.04 \mathrm{~kg}$ of DM/goat for floor-level, head-level, and elevated-level feeders, respectively). Total feeding time did not vary with feeder height, but feeding rate tended to be faster at the elevated-level feeder (14.5 \pm $2.1 \mathrm{~g}$ of $\mathrm{DM} / \mathrm{min})$ compared with head-level $(9.2 \pm 2.3$ $\mathrm{g}$ of $\mathrm{DM} / \mathrm{min})$ and floor-level $(8.9 \pm 2.1 \mathrm{~g}$ of $\mathrm{DM} / \mathrm{min})$ feeders. Goats visited the floor-level feeder $(36.4 \pm 8.4$ visits/goat) less than the head-level (79.4 \pm 8.4 visits/ goat) and elevated-level (74.8 \pm 8.4 visits/goat $)$ feeders. The number of displacements per minute of feeding time (physical removal of another goat from the feeding place) was greater at the elevated-level feeder $(0.46 \pm$ 0.06 displacements $/ \mathrm{min}$ ) compared with the floor-level feeder $(0.23 \pm 0.06$ displacements $/ \mathrm{min})$ and tended to differ from the head-level feeder $(0.27 \pm 0.06$ displace-
\end{abstract}

Received October 3, 2017.

Accepted December 22, 2017.

${ }^{1}$ Corresponding author: gosia.zobel@agresearch.co.nz ments/min). We conclude that goats eat more from an elevated feeder and compete more to access this feeder. Key words: foraging, natural behavior, welfare, browsing

\section{INTRODUCTION}

Goats are selective foragers of "browse" (e.g., foliage, buds, flowers, and stems of shrubbery; Askins and Turner, 1972). Although this browsing behavior can include some low-level feeding, different body positions are used to access the browse when located at variable heights; these positions include eye-level feeding and rearing onto the rear legs (Tölü et al., 2012). The inclusion of browsing behavior allows for an expansion of the foraging area by accessing browse above head level. There is a wealth of evidence indicating that when goats are faced with a variety of browse, forbs, and grasses in their environment, they will consume a diet containing much more browse than sheep or cattle (reviewed by Goetsch et al., 2010; Solaiman, 2010). Sanon et al. (2007) reported that goats browsed forage that was located on average at a height of $1.65 \mathrm{~m}$ (maximum $=2.1 \mathrm{~m}$ )-more than double their body height. Goats have also been reported to climb trees when given the opportunity (El Aich et al., 2007). Feeding with the head elevated may aid in predator detection; grazing with the head lowered is known to limit visual identification of threats (Beauchamp, 2015). Feeding at head or elevated level may also reduce the risk of infection, as parasite eggs are typically situated at or near ground level (Lu, 1988).

Extensively managed goats housed in complex naturalistic environments will browse for a considerable portion of their daily feeding time. However, when intensively managed on commercial farms, goats are typically fed using a floor-level feeder. In cattle, different feed bunk designs can affect aggression (DeVries and von Keyserlingk, 2006), feeding time (Huzzey et al., 2006), and access to the feed bunk for subordinate animals (Endres et al., 2005). There have been limited studies on feeder design for goats. Aschwanden et al. (2009a) showed reduced aggression between goats when 
partitions between feeding places were provided; however, it has been suggested that some partitions may restrict goat mobility into and out of the feed bunk (Nordmann et al., 2011a).

Few studies have investigated the effect of feeder height on feeding and social behavior of goats. Aschwanden et al. (2009a) allowed goats to feed from a vertically elongated hayrack that required them to stand on a platform and found decreased agonistic behavior and increased feeding time compared with feeding at floor level. In a companion study, Aschwanden et al. (2009b) found that goats provided housing containing structural elements, including elevated platforms for feeding, had longer feeding bouts and fewer interrupted resting bouts. The structure of feed bunks has also been adjusted to allow for a comfortable posture and reach while feeding (Keil et al., 2017). However, these studies did not offer elevated feeders that resemble heights found in natural browsing situations, nor did they allow multiple goats to feed together from the same height. Elevated feeding areas that resemble how goats naturally forage may be preferred and promote increased feed intake.

The objective of this study was to determine whether goats prefer to feed from a browsing position. We predicted that goats would consume more feed and spend more time feeding from feeders that permit a browsing position. Furthermore, we expected that more competitive displacements would occur at the higher feeders as a result of the preference for these feeding positions. Overall, our aim was to evaluate the effects of offering dairy goats an elevated surface for feeding.

\section{MATERIALS AND METHODS}

The study was conducted in August 2016 at the Ruakura Research Centre in Hamilton, New Zealand. All procedures were approved by the Ruakura Animal Ethics Committee (Hamilton, New Zealand; no. AE13930) under the New Zealand Animal Welfare Act 1999 and by the University of British Columbia Animal Care Committee (Vancouver, BC, Canada; no. A16-0213).

\section{Animals, Housing, and Diet}

Thirteen nonlactating, nulliparous, nonpregnant, and disbudded Saanen X dairy goats were enrolled from the AgResearch herd at approximately 13 mo of age with a mean $( \pm \mathrm{SD}) \mathrm{BW}$ of $37.6 \pm 3.6 \mathrm{~kg}$. Goats were previously housed on pasture as a single group and were given $6 \mathrm{~d}$ to habituate to the indoor facility. This began with an initial period of indoor housing at night only, followed by $5 \mathrm{~d}$ of continuous indoor housing. Goats were then housed as a single group for the next $24 \mathrm{~d}$ in a home pen with plywood walls measuring $11.3 \times 3.0 \mathrm{~m}$ (offering $2.6 \mathrm{~m}^{2}$ /goat); half of the pen was equipped with a plywood box bedded $40 \mathrm{~cm}$ deep with wood shavings (offering $1.3 \mathrm{~m}^{2}$ /goat), and the other half of the pen floor was metal grating (Figure 1). In the home pen, goats were fed ad libitum alfalfa silage (Fiber Protect, Fiber Fresh Feeds, Reporoa, New Zealand) top-dressed with $3 \mathrm{~kg}$ of pellets $(0.23 \mathrm{~kg} /$ goat; Fiber Grow, Dunstan Horse Feeds Ltd., Hamilton, New Zealand) twice daily at 0800 and $1600 \mathrm{~h}$ (per requirements for 40-kg nonlactating goat; NRC, 2007). Feed was provided from 1 of 3 feeder heights (floor, head, and elevated levels; see Figure $2 \mathrm{~A}-\mathrm{C}$ for design details). Each morning at 0800 $\mathrm{h}$, the feeder height was changed to a different feeder height following a randomized schedule such that only 1 feeder height was offered during a given 24-h period. Goats received fresh water from a wall-mounted waterer, and ad libitum hay was provided and replenished daily at $1200 \mathrm{~h}$ in 2 hayracks positioned at $72 \mathrm{~cm}$ above the pen floor at either end of the pen.

\section{Experimental Design}

Following $24 \mathrm{~d}$ in the home pen, individual preference for feed bunk height was tested over $10 \mathrm{~d}$. On the first day, all goats were moved as a group to the test pen for $24 \mathrm{~h}$ of habituation. The test pen was identical to the home pen except that all 3 feeder heights were offered simultaneously. Goats were able to choose which feeder to feed from and could feed alongside other goats if they wished (offering $20 \mathrm{~cm}$ of feeding space per goat per feeder). Feed offered in the test pen was identical to that offered in the home pen, with each feeder providing ad libitum chopped alfalfa silage top-dressed with $0.23 \mathrm{~kg}$ of pellets/goat refreshed at 0800 and $1600 \mathrm{~h}$ each day.

Following the 24-h habituation period in the test pen, all the goats were returned to the home pen. Over the next 9 d, 3 goats were selected each morning before feeding to enter the test pen, where they remained for $24 \mathrm{~h}$. Goats were selected pseudorandomly such that all goats entered the test pen as a triad at least twice, but no goat remained in the test pen for 2 consecutive days and all triads were unique. The order of feeder heights presented from left to right was changed each morning; order was randomized such that each combination was presented at least once and no more than twice over the 9-d testing period. At each feeding, feed refusals from inside each feeder were collected and weighed to calculate feed intake. Any feed that fell out of the feeder was collected from a tray that was placed underneath each feeder under the metal grating of the pen and added to the total refusals calculation. Samples of of- 
fered feed from each feeder height were collected daily. All samples were frozen before nutrient analysis (Hill Laboratories, Hamilton, New Zealand). The nutritional content of silage offered did not differ among floor-level (DM: $41.8 \pm 1.7 \%$, CP: $18.5 \pm 1.0 \%$ of DM, ADF: 34.7 $\pm 2.6 \%$ of DM, NDF: $43.7 \pm 3.6 \%$ of DM, and ME: 8.9 $\pm 0.5 \mathrm{MJ} / \mathrm{kg}$ of $\mathrm{DM}$ ), head-level (DM: $41.9 \pm 1.8 \%$, CP: $18.7 \pm 1.0 \%$ of DM, ADF: $34.4 \pm 2.6 \%$ of DM, NDF: $42.9 \pm 3.3 \%$ of DM, and ME: $9.0 \pm 0.5 \mathrm{MJ} / \mathrm{kg}$ of $\mathrm{DM}$ ), and elevated-level (DM: $42.0 \pm 1.9 \%$, CP: $18.8 \pm$ $0.7 \%$ of DM, ADF: $34.0 \pm 2.0 \%$ of DM, NDF: $42.6 \pm$ $2.7 \%$ of DM, and ME: $9.1 \pm 0.4 \mathrm{MJ} / \mathrm{kg}$ of $\mathrm{DM}$ ) feeders over the duration of the experiment.

\section{Behavioral Measures}

Behavior at each feeder was recorded using video cameras [DS-2CD2432F-I(W), HikVision, Zhejiang, China] attached to a HikVision NVR (DS-7732N1-14/16P). Goats were color marked on their back (Tell Tail paint, FIL NZ Ltd., Mount Maunganui, New Zealand) to identify individuals for behavioral observations on video recordings. One goat of each triad was randomly selected as the focal animal for observation on each day using a random number generator, resulting in a total of 9 focal goats; no goat was a focal animal more than once. Feeding time at each feeder height (i.e., muzzle of the goat was inside the feeder) and the total number of displacements at the feeder (i.e., the number of times the feeding focal goat physically displaced another goat from the feeder + the number of times the feeding focal goat was physically displaced from the feeder by another goat) were continuously recorded for $24 \mathrm{~h}$ for each focal goat. Because a goat needed to be present at the feeder to be involved in a displacement event, we report the number of displacements at each feeder
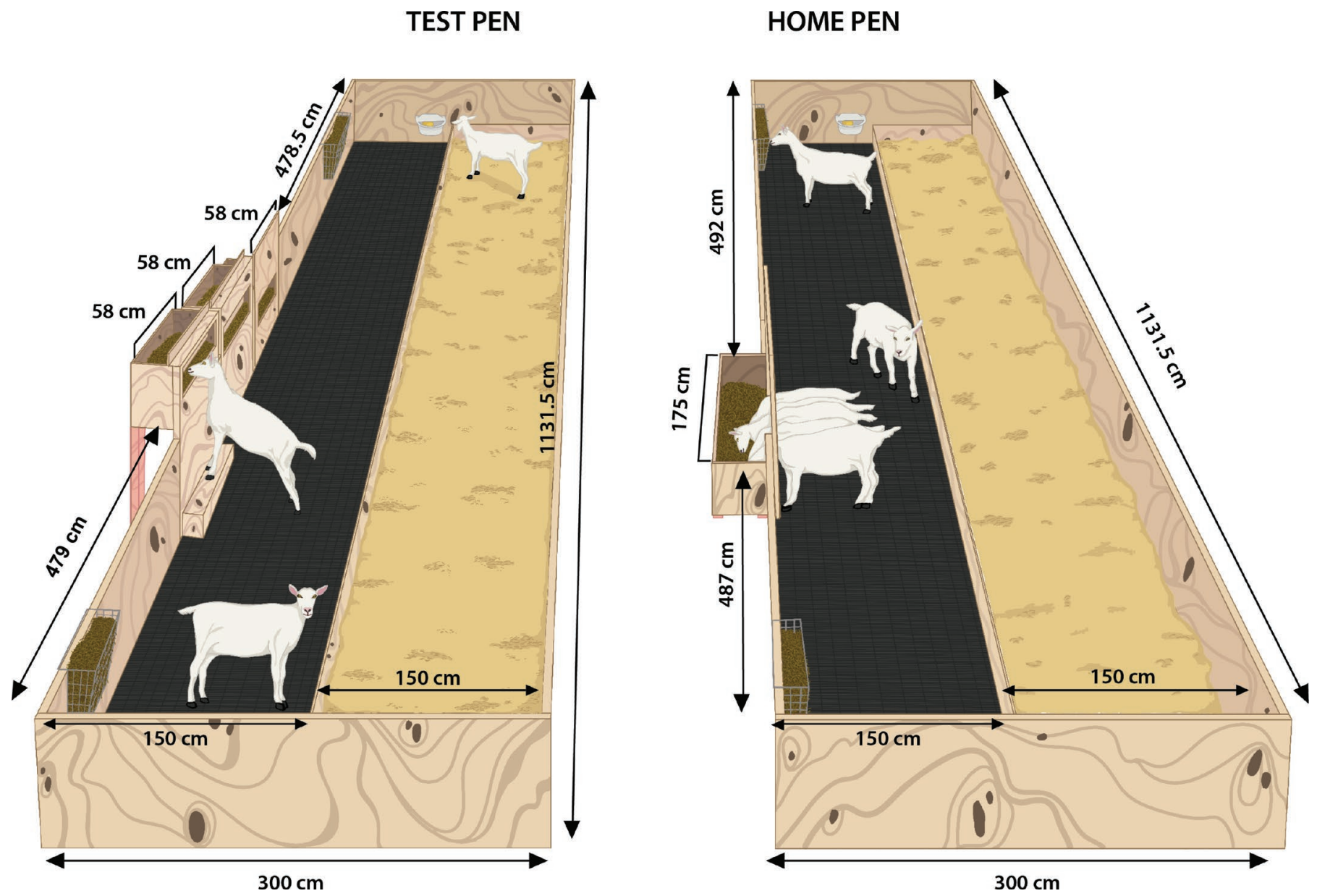

Figure 1. Layout of the test and home pens. Dimensions were identical for the 2 pens. The home pen contained a single feeder $175 \mathrm{~cm}$ in length; each day the height of this feeder was varied (floor level, head level, and elevated level) to familiarize the goats with the 3 feeding positions. The test pen contained 3 smaller feeders, one of each feeder height. Each was $58 \mathrm{~cm}$ long, mounted $11.5 \mathrm{~cm}$ apart, and centered along the length of the pen. 
A

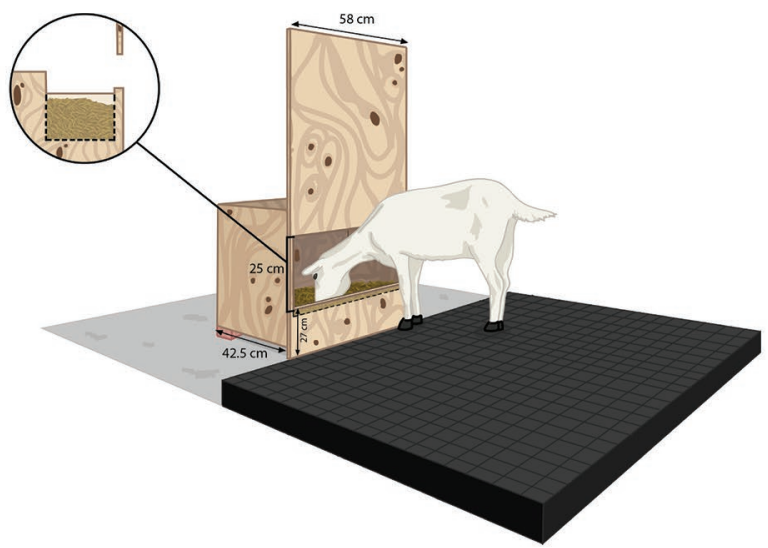

B

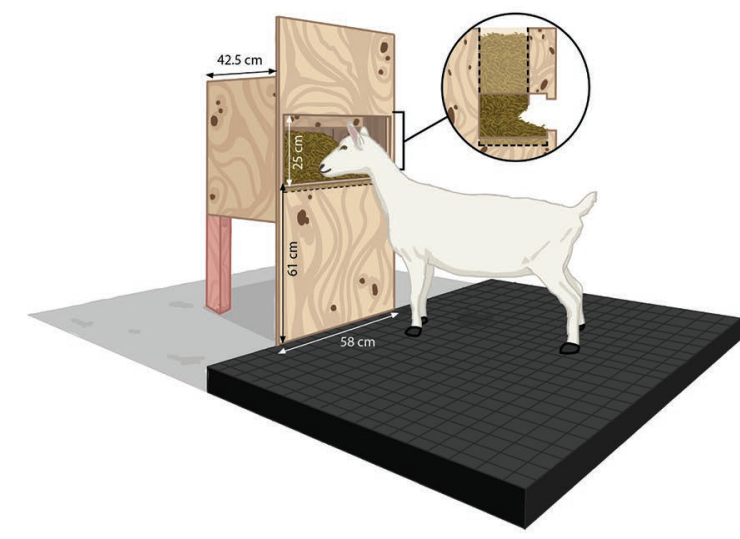

C

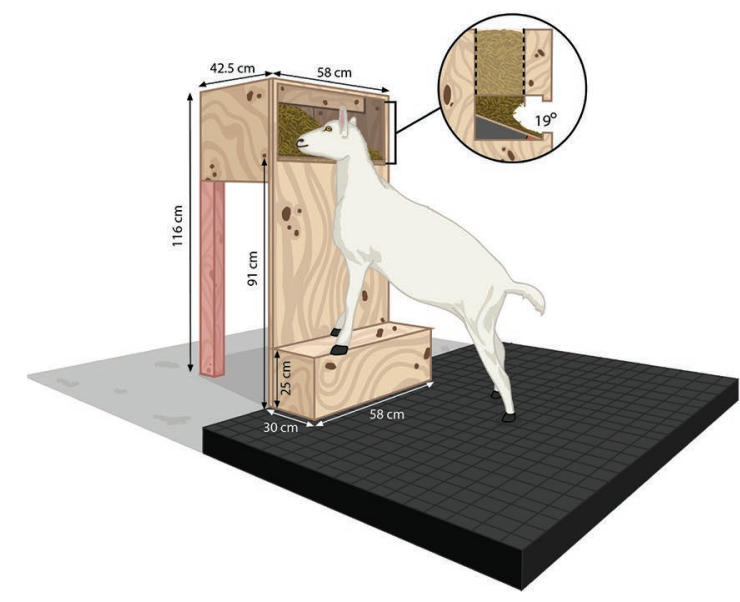

Figure 2. Detailed schematics for the 3 feeders used in the test pen. (A) Floor level: goat's head is lowered to the ground when feeding to mimic grazing; feeder opening is $27 \mathrm{~cm}$ from the pen floor; feed table is at hoof level. (B) Head level: goat's head is level and parallel to the pen floor when feeding to mimic browsing; feeder opening and feed table are $61 \mathrm{~cm}$ from pen floor. (C) Elevated level: goat's head and body are angled upward with the front 2 hooves standing on a raised wooden step attached at the base of the feeder, designed to mimic browsing; feeder opening is $91 \mathrm{~cm}$ from the pen floor; feed table is angled at $19^{\circ}$. All feeders were fitted with a wooden frame through which the goats could access feed. For the floor-level feeder, the wooden frame also acted as a neck rail, similar to that used in studies of feeding behavior (Nordmann et al., 2011b) and on some commercial farms. height as a ratio of feeding time at that particular feeder height (i.e., number of displacements per minute of feeding time). Feeding rate was calculated from total feed intake and feeding time. When the goat removed its muzzle from the feeder for longer than $2 \mathrm{~s}$, a new visit was counted, and we recorded the total number of feeding visits for each goat.

\section{Statistical Analysis}

All statistical analyses were performed with SAS (version 9.4; SAS Institute Inc., Cary, NC) using goat or triad as the experimental unit. All the variables were screened using the UNIVARIATE procedure using box, distribution, and probability plots and confirmed for normality. Feed intake for each triad over the 24-h observation period was calculated on a DM basis and averaged per goat ( $\mathrm{kg}$ of $\mathrm{DM})$. Total feeding time (min), feeding rate (g of DM/min), visits (no.), and displacements after adjusting for feeding time (no./min of feeding time) were summarized for each focal goat for the 24 -h period. All outcome variables were analyzed in a mixed model with the fixed effects of feeder height (floor, head, and elevated level), BW (average weight of the triad for the feed intake variable; focal goat weight for behavior variables), and feeder presentation order (6 combinations). The covariates BW and feeder presentation order were dropped from the model if $P>$ 0.1. Group was specified as a random effect. Treatment differences between all pairwise comparisons of feeder heights were tested using a Bonferroni adjustment. Results are reported as least squares means and standard error. Significance was set at $P \leq 0.05$, and tendency was set at $0.05<P \leq 0.1$.

\section{RESULTS}

Feed intake ( $\mathrm{kg}$ of $\mathrm{DM})$ increased with increasing feeder height $\left(F_{2,16}=4.42 ; P=0.03\right)$ such that intake was highest at the elevated level compared with the floor level but did not differ between elevated- and head-level feeders or between head- and floor-level feeders (Figure 3a). Feeding time (min) did not vary with feeder height $\left(F_{2,16}=1.39 ; P=0.3\right.$; Figure $\left.3 b\right)$. Feeder height tended to affect feeding rate (g of DM/min; $F_{2,15}$ $=2.7 ; P=0.1$ ), but no pairwise differences between feeders were found (Figure 3c). The number of visits to the feeder was affected by feeder height $\left(F_{2,16}=6.7 ; P<\right.$ 0.01 ), with the lowest number of visits at the floor-level feeder compared with head- and elevated-level feeders (Figure 3d). Feeder height also affected the number of displacements (no./min of feeding time) at each feeder $\left(F_{2,16}=5.30 ; P=0.02\right)$, with the greatest number of displacements at the elevated level (Figure 3e). 


\section{DISCUSSION}

This study examined how providing goats a choice between different feeding heights can affect feeding and social behavior. We found that goats consumed more feed at a higher feeding rate from the elevated feeders. Goats were least likely to visit the floor-level feeder and were most likely to competitively displace one another at the highest feeder, suggesting that the animals were motived to feed from higher locations. In contrast with
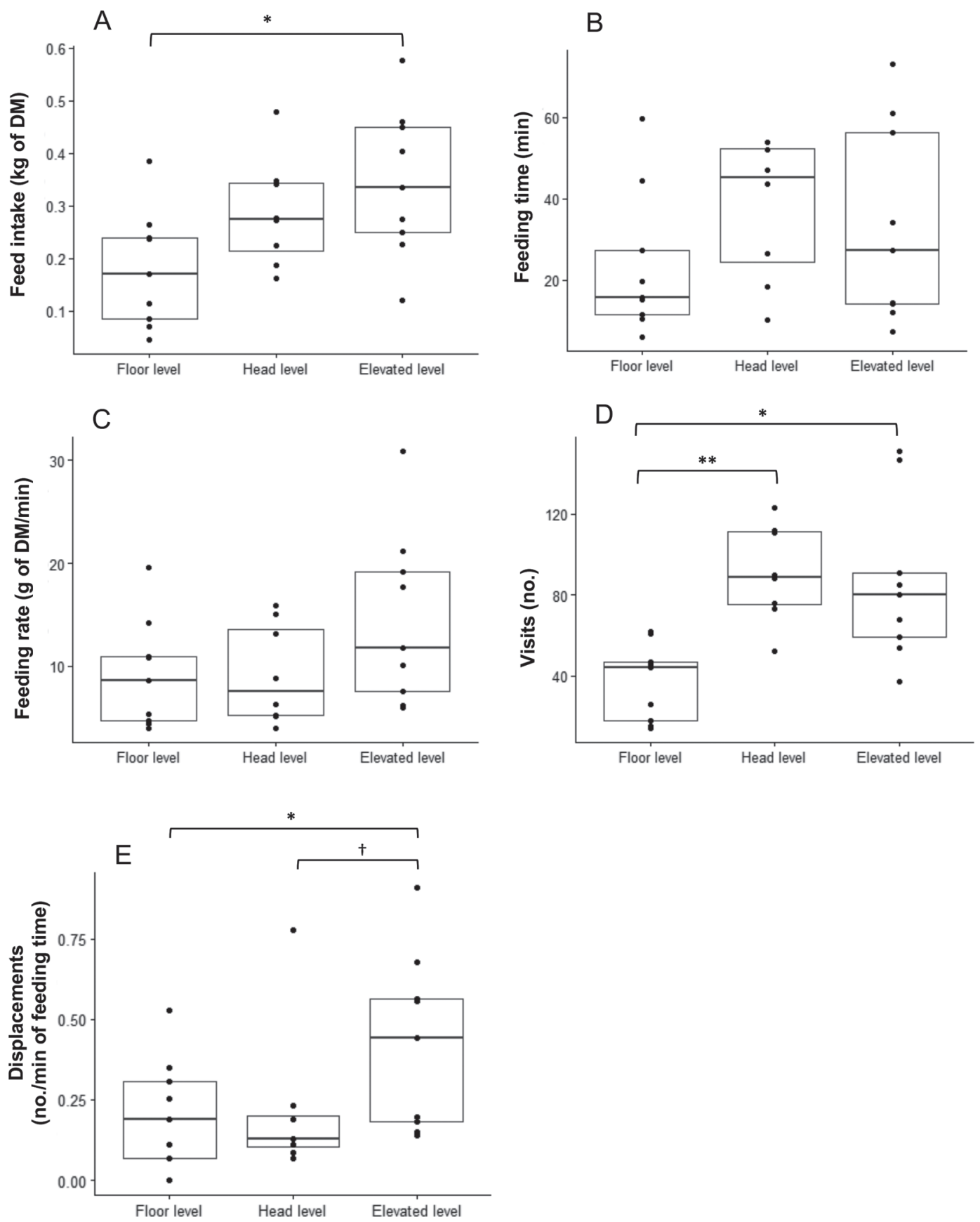

Figure 3. Feeding and social behavior measures (mean \pm SE) over a 24 -h observation period when goats were housed in triads $(\mathrm{n}=9$ triads) and offered one of each feeder height (floor level, head level, and elevated level). Goats were able to feed from any feeder, and all goats could feed from the same feeder if desired. Results are shown separately for (A) DMI (kg of DM), (B) feeding time (min), (C) feeding rate (g of DM/ $\min$ ), (D) visits to the feeder (no.), and (E) displacements (no./min of feeding time). Significant differences between feeder heights are indicated by ${ }^{* *} P \leq 0.01$ and ${ }^{*} P \leq 0.05$ and tendencies by $\dagger 0.05<P \leq 0.1$. Feed intake was measured per triad and averaged for each goat; all other measurements were performed on 1 focal goat per triad. 
the findings of the current study, Dziba et al. (2003) found no difference in DMI when foliage branches of different heights were offered indoors; however, this finding should be viewed with caution given that goats were observed for only a 3 -min period.

We found that feeding height tended to affect feeding rate. This is similar to Dziba et al. (2003), who found that intake rate increased with increasing feeding height. Intake rate was primarily driven by increased bite size at higher feeding heights. Neither study found differences in feeding time at higher feeder heights. Increased intake without changes in feeding time at the elevated-level feeder in the current study may be explained by the increased feeding rate. Other work has shown that goats generally consumed more DM when foliage is hanging compared with when foliage is in a trough, with no differences in feeding time (Van et al., 2005).

An increase in bite rate at higher feeding heights may be explained by the natural browsing behavior and oral morphology of goats. In their natural environment, goats will typically browse on shrub species that have tender small leaves; this type of foraging requires successive bites to sever the leaves rather than a single bite (Mellado et al., 2007). Goats have a narrow mouth, a mobile upper lip, and shorter jaws (relative to many other ruminant species) that allow them to be highly selective while foraging and chew faster (Pérez-Barbería and Gordon, 1999; Mellado et al., 2007). Thus, feeding at increased feeding heights may promote natural selective foraging behavior, resulting in increased intake per unit of time.

We also observed more displacements at the elevated feeder. Other studies have reported social behavior of indoor goats that could feed from platforms. Aschwanden et al. (2009b) housed goats in dyads in which one goat could feed at ground level and the other could feed by standing on top of a platform ranging from 25 to $80 \mathrm{~cm}$ high. The rate of agonistic interactions was lower on higher platforms $(50$ and $80 \mathrm{~cm}$ ), perhaps because these platforms increased the physical distance between feeding goats and provided limited standing room, making it difficult for multiple goats to stand together. In our study, the elevated-level feeder could be accessed by multiple goats, all from a stable standing position, with limited risk of falling. However, if all 3 goats were at a single feeder, this resulted in just $20 \mathrm{~cm}$ of feeding space per animal-less than the suggested recommendation of $50 \mathrm{~cm}$ for hornless goats (Loretz et al., 2004). This feeding environment may have inflated the number of displacements observed at each of the feeders in our experiment. We suggest that elevated feeders do not increase displacements per se, but rather that the increased competition reflects the motivation to access this limited resource. This finding highlights the importance of offering adequate space to allow for all individuals to feed when and where they want at the feed bunk; ample feeding space may be especially important in cases where goats are more likely to engage in aggressive behavior, such as if goats are horned or if goats are mixed as adults (Loretz et al., 2004; Aschwanden et al., 2008).

An elevated feeder allows for quadrupedal browsing, a natural foraging behavior by goats. When managed on rangeland, Angora goats spent a third of their time grazing and the remaining time browsing (Askins and Turner, 1972). Sanon et al. (2007) reported that goats browsed for more than $60 \%$ of their feeding time during the rainy season and for more than $90 \%$ of their feeding time during the dry season when the herbaceous component began to decline (Sanon et al., 2007). In nonpregnant and nonlactating goats, browse composed the majority of reported dietary intake (Mellado et al., 2005). One study showed that the majority of browsing time was spent in the quadrupedal position (Pfister et al., 1988). These authors reported that 46,20 , and $44 \%$ of foraging time was spent in the quadrupedal position during the mid-dry, late-dry, and wet seasons, respectively. Goats spent as much as $8 \%$ of their foraging time in the bipedal position during the wet season despite abundant forage sources in lower strata (Pfister et al., 1988). We suggest that this type of natural foraging behavior should be considered when designing indoor commercial feeding systems.

The feeders in our experiment mimicked a commercial feeding system allowing animals to move freely along the feed bunk. This design may permit greater displacements between feeding goats compared with other commercial feeding systems (Nordmann et al., 2011a). Other work investigating modified feed bunk designs showed that the feed table must be raised at least $10 \mathrm{~cm}$ to allow for goats to feed in a relaxed posture while also reaching all of the feed in the manger (Keil et al., 2017). Head-level or elevated-level feeder designs can feasibly be implemented in commercial settings by lowering the pen floor relative to the feed bunk; in fact, some commercial systems have implemented such designs (Figure 4). A notable design feature of our feeders was the use of a wooden frame above the goats' heads, which was intended to reduce potential distractions outside the pen. Although many commercial farms use a wooden frame as a neck rail, it is less common to have a solid frame above the goats' heads. We recognize that this design feature may have had some influence on the feeding behavior of the goats. We encourage future work to develop and test different designs of elevated feeders that consider ease of feed delivery for the farmer, minimize competitive interac- 


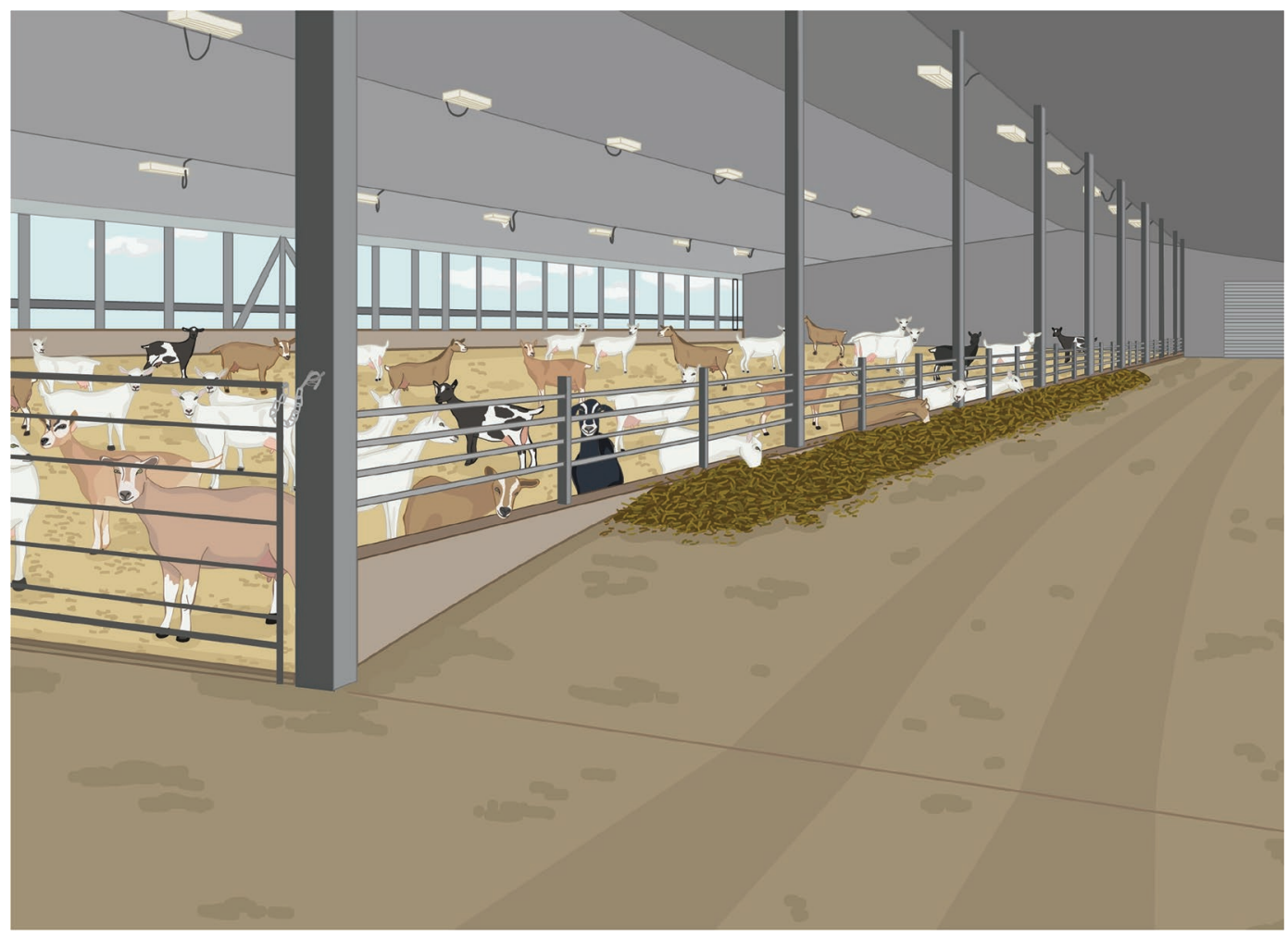

Figure 4. Schematic drawing of a head- or elevated-level feed bunk design used on some commercial farms (based on the design of Henry and Anja van der Vlies and family, Ontario, Canada). Primary features include a driving alley with a ramp up to an elevated feed bunk and the pen floor being lower relative to the feed bunk. Goats are able to feed with their head and feet raised.

tions, and maximize appropriate feeding posture and comfort for the goats.

In conclusion, goats will choose to eat from a variety of feeder heights but show a preference for an elevated feeder height. Dairy goats may benefit from the availability of raised feeders that promote natural browsing behaviors.

\section{ACKNOWLEDGMENTS}

We are grateful to Ian Johnston (AgResearch Ltd., Hamilton, New Zealand) for his assistance in the design and installation of the experimental setup and to Bridget Wise (AgResearch Ltd.) for assistance in data collection. We also thank Suzanne Dowling (AgResearch Ltd.) for her time spent watching video and Henry and Anja van der Vlies and family (Ontario, Canada) for using their barn design as a model for Figure 4 . We also thank the anonymous reviewers who encouraged us to highlight the novelty of this work and provided positive constructive comments that improved this manuscript. Heather Neave was supported by the Natural Science and Engineering Research Council Canada Graduate Scholarship and the Michael Smith Foreign Study Supplement. Funding for the study was provided by the New Zealand Ministry of Business, Innovation and Employment (Wellington, New Zealand; C10X1307) and the Dairy Goat Co-Operative (NZ) Ltd. (Hamilton, New Zealand).

\section{REFERENCES}

Aschwanden, J., L. Gygax, B. Wechsler, and N. M. Keil. 2008. Social distances of goats at the feeding rack: Influence of the quality of social bonds, rank differences, grouping age and presence of horns. Appl. Anim. Behav. Sci. 114:116-131. https://doi.org/10.1016/j .applanim.2008.02.002.

Aschwanden, J., L. Gygax, B. Wechsler, and N. M. Keil. 2009a. Structural modifications at the feeding place: Effects of partitions and platforms on feeding and social behaviour of goats. Appl. Anim. Behav. Sci. 119:180-192. https://doi.org/10.1016/j.applanim.2009 .04 .004 .

Aschwanden, J., L. Gygax, B. Wechsler, and N. M. Keil. 2009b. Loose housing of small goat groups: Influence of visual cover and elevated levels on feeding, resting and agonistic behaviour. Appl. Anim. Behav. Sci. 119:171-179. https://doi.org/10.1016/j.applanim.2009 .04 .005 .

Askins, G. D., and E. E. Turner. 1972. A behavioral study of Angora goats on West Texas range. J. Range Manage. 25:82-87. https:// doi.org/10.2307/3896790.

Beauchamp, G. 2015. Animal Vigilance: Monitoring Predators and Competitors. Academic Press, San Diego, CA.

DeVries, T. J., and M. A. G. von Keyserlingk. 2006. Feed stalls affect the social and feeding behavior of lactating dairy cows. J. Dairy Sci. 89:3522-3531. https://doi.org/10.3168/jds.S0022 -0302(06)72392-X. 
Dziba, L., P. Scogings, I. Gordon, and J. Raats. 2003. The feeding height preferences of two goat breeds fed Grewia occidentalis L. (Tiliaceae) in the Eastern Cape, South Africa. Small Rumin. Res. 47:31-38. https://doi.org/10.1016/S0921-4488(02)00234-1.

El Aich, A., N. El Assouli, A. Fathi, P. Morand-Fehr, and A. Bourbouze. 2007. Ingestive behavior of goats grazing in the Southwestern Argan (Argania spinosa) forest of Morocco. Small Rumin. Res. 70:248-256. https://doi.org/10.1016/j.smallrumres.2006.03.011.

Endres, M. I., T. J. DeVries, M. A. G. von Keyserlingk, and D. M. Weary. 2005. Short communication: Effect of feed barrier design on the behavior of loose-housed lactating dairy cows. J. Dairy Sci. 88:2377-2380. https://doi.org/10.3168/jds.S0022-0302(05)72915 -5 .

Goetsch, A. L., T. A. Gipson, A. R. Askar, and R. Puchala. 2010. Invited review: Feeding behavior of goats. J. Anim. Sci. 88:361-373. https://doi.org/10.2527/jas.2009-2332.

Huzzey, J. M., T. J. DeVries, P. Valois, and M. A. G. von Keyserlingk. 2006. Stocking density and feed barrier design affect the feeding and social behavior of dairy cattle. J. Dairy Sci. 89:126-133. https://doi.org/10.3168/jds.S0022-0302(06)72075-6.

Keil, N. M., M. Pommereau, A. Patt, B. Wechsler, and L. Gygax. 2017. Determining suitable dimensions for dairy goat feeding places by evaluating body posture and feeding reach. J. Dairy Sci. 100:1353-1362. https://doi.org/10.3168/jds.2016-10980.

Loretz, C., B. Wechsler, R. Hauser, and P. Rüsch. 2004. A comparison of space requirements of horned and hornless goats at the feed barrier and in the lying area. Appl. Anim. Behav. Sci. 87:275-283. https://doi.org/10.1016/j.applanim.2004.01.005.

$\mathrm{Lu}$, C. D. 1988. Grazing behavior and diet selection of goats. Small Rumin. Res. 1:205-216. https://doi.org/10.1016/0921-4488(88)90049 -1 .

Mellado, M., L. Olivares, W. Pittroff, H. Díaz, R. López, and J. A. Villarreal. 2007. Oral morphology and dietary choices of goats on rangeland. Small Rumin. Res. 71:194-199. https://doi.org/10 $.1016 /$ j.smallrumres.2006.06.005.

Mellado, M., A. Rodriguez, J. A. Villarreal, and A. Olvera. 2005. The effect of pregnancy and lactation on diet composition and dietary preference of goats in a desert rangeland. Small Rumin. Res. 58:79-85. https://doi.org/10.1016/j.smallrumres.2004.07.014.

NRC. 2007. Nutrient Requirements of Small Ruminants: Sheep, Goats, Cervids, and New World Camelids. National Academies Press, Washington, DC.

Nordmann, E., N. M. Keil, C. Schmied-Wagner, C. Graml, J. Langbein, J. Aschwanden, J. von Hof, K. Maschat, R. Palme, and S. Waiblinger. 2011a. Feed barrier design affects behaviour and physiology in goats. Appl. Anim. Behav. Sci. 133:40-53. https://doi .org/10.1016/j.applanim.2011.04.016.

Nordmann, E., N. M. Keil, C. Schmied-Wagner, C. Graml, J. Langbein, J. Aschwanden, J. von Hof, K. Maschat, R. Palme, and S. Waiblinger. 2011b. Feed barrier design affects behaviour and physiology in goats. Appl. Anim. Behav. Sci. 133:40-53. https://do .org/10.1016/j.applanim.2011.04.016.

Pérez-Barbería, F. J., and I. J. Gordon. 1999. The functional relationship between feeding type and jaw and cranial morphology in ungulates. Oecologia 118:157-165. https://doi.org/10.1007/ s004420050714.

Pfister, J. A., J. C. Malechek, and D. F. Balph. 1988. Foraging behaviour of goats and sheep in the Caatinga of Brazil. J. Appl. Ecol. 25:379-388. https://doi.org/10.2307/2403830.

Sanon, H. O., C. Kaboré-Zoungrana, and I. Ledin. 2007. Behaviour of goats, sheep and cattle and their selection of browse species on natural pasture in a Sahelian area. Small Rumin. Res. 67:64-74. https://doi.org/10.1016/j.smallrumres.2005.09.025.

Solaiman, S. G. 2010. Goat Science and Production. Wiley-Blackwell, Ames, IA.

Tölü, C., İ. Y. Yurtman, H. Baytekin, C. Ataşoğlu, and T. Sava. 2012 Foraging strategies of goats in a pasture of wheat and shrubland. Anim. Prod. Sci. 52:1069-1076. https://doi.org/10.1071/AN11251.

Van, D. T. T., N. T. Mui, and I. Ledin. 2005. Tropical foliages: Effect of presentation method and species on intake by goats. Anim. Feed Sci. Technol. 118:1-17. https://doi.org/10.1016/j.anifeedsci .2004 .10 .016 . 